\title{
Mechanical Property and Fracture Behavior of Al/Mg Composite Produced by Accumulative Roll Bonding Technique
}

\author{
Chih-Chun Hsieh, Ming-Che Chen, and Weite Wu \\ Department of Materials Science and Engineering, National Chung Hsing University, 250 Kuo-Kuang Road, Taichung 402, Taiwan \\ Correspondence should be addressed to Weite Wu; wwu@dragon.nchu.edu.tw
}

Received 9 January 2013; Accepted 15 July 2013

Academic Editor: Harry Siu-lung Ku

Copyright ( 2013 Chih-Chun Hsieh et al. This is an open access article distributed under the Creative Commons Attribution License, which permits unrestricted use, distribution, and reproduction in any medium, provided the original work is properly cited.

\begin{abstract}
The $\mathrm{Al} / \mathrm{Mg}$ laminated composite was fabricated by an accumulative roll bonding (ARB) technique using Al-1100 and Mg-AZ31 at $573 \mathrm{~K}$. Tensile properties along rolling direction under different ARB cycles were evaluated at the ambient temperature. The tensile strength of the $\mathrm{Al} / \mathrm{Mg}$ composite increased gradually till three ARB cycle and then decreased after the fourth ARB cycles. Scanning electron microscopy (SEM) was used to investigate the microstructure evolution and the failure mechanism. The Al/Mg interface with interface angles between $30^{\circ}$ and $35^{\circ}$ has minimum tensile strength. A higher or lower interface angle improves the tensile strength, and the interface angle can be reduced by increasing the number of cycles in the ARB process. Thus, the crack at the coarse intermetallic compounds and rupture of the Al layer after fourth cycle caused the premature failure of the specimens during the tensile test.
\end{abstract}

\section{Introduction}

In recent times, the deformation and stability of metallic multilayers and the elastic and plastic behavior of multilayers under stress are increasingly being studied by researchers. Despite a broad range of investigations that include, for example, the study of the dislocation behavior in nanoscale multilayers $[1,2]$, a common feature of most such studies is that the true strain involved in the deformation process is less than approximately 1 . Due to the limited strain involved, substantial changes in the layer arrangement and layer thickness are rarely encountered.

Processing of fine-grained microstructures, even amorphous phases, by severe plastic deformation (SPD) has received considerable interest as a technique for strengthening metallic materials without a substantial degradation of ductility. Fine-grained microstructures of many kinds of metallic materials have been obtained by SPD techniques. A novel intense straining process involved in SPD for bulk materials using rolling deformation, termed accumulative roll bonding (ARB), was developed recently [3-6]. In this process, the achieved strain is theoretically unlimited. The ARB process has been successfully applied to aluminum alloy systems [7-10], steel systems [11, 12], copper systems [13], and layer-composite systems [14-16]. Most materials processed by ARB in several cycles have structures with submicron grains and show very high strength at ambient temperature [7-11]. Al/Mg layer compounds were successfully produced via an ARB process [14]. Al/Mg layer compounds exhibited excellent mechanical properties and showed refined grains. Diffusion occurred at the interface of $\mathrm{Al}$ and $\mathrm{Mg}$ and resulted in excellent bonding during the ARB process. An intermetallic compound (IMC) was formed, which affected the interface properties after sufficient diffusion had occurred [17]. Between the bonding materials, atoms diffuse each other usually occur during a hot roll bonding process [14]. In order to understand the mechanism of formation of intermetallic compounds during the diffusion bonding of dissimilar metals, understanding the law of interdiffusion at the interface is necessary. Moreover, a proper application of this technique can improve the adhesion strength of dissimilar metals during the diffusion process $[18,19]$.

In our previous study, the accumulative roll bonding (ARB) process was used with a snap-stack procedure to reduplicate $\mathrm{Al}-1100$ and $\mathrm{Mg}$-AZ31 alloys $[14,20,21]$. The $\mathrm{ARB}$ process creates a multilayer compound between $\mathrm{Al} / \mathrm{Mg}$ 
layers with excellent bonding characteristics. The first and second cycles of the ARB process did not result in IMC, but the IMC produced in specimens after the third and fourth cycles $[14,20,21]$. Two intermetallic compounds of $\mathrm{Al}_{3} \mathrm{Mg}_{2}$ and $\mathrm{Al}_{12} \mathrm{Mg}_{17}$ were formed and identified at interface of composite layer [20,21]. In this study, the tensile strength of an $\mathrm{Al} / \mathrm{Mg}$ alloy compound was determined after a tensile test. The parameters of ultimate tensile strength, elongation, resultant stress, and critical transformation angle were obtained. The microstructure at the interface of $\mathrm{Al}$ and $\mathrm{Mg}$ was analyzed using an optical microscope (OM) and a scanning electron microscope (SEM).

\section{Experimental Procedure}

The materials used in this study were pure aluminum (A1100) and magnesium alloy (AZ31). The sheet dimensions were $1 \mathrm{~mm}$ (thickness) $\times 20 \mathrm{~mm}$ (width) $\times 200 \mathrm{~mm}$ (length) Figure 1 shows the principle of the ARB process. Three sheets were stacked after degreasing with acetone and a sandblasting surface treatment. They were then roll-bonded to a $50 \%$ reduction in thickness by one pass without lubricant at $573 \mathrm{~K}$. Reheating was carried out at $573 \mathrm{~K}$ for $90 \mathrm{~s}$ before each ARB degreasing and sand spraying step, which were required for achieving good bonding to create a single body of solid material. The roll-bonded sheet was cut into two sheets with the initial dimensions, and they were then stacked and rolled again. The thickness reduction per cycle was 50\%, and this was repeated for the first, second, third, and fourth cycles. The strains of the first, second, third, and fourth cycles were equivalent to von Mises strains, $\varepsilon v \mathrm{M}$, of $0.8,1.6,2.4$, and 3.2, respectively.

Tensile properties of the ARB materials were determined using standard round specimens. To determine the local variation of tensile properties from the different cycles of ARB specimens, ARB tensile specimens $(1.5 \mathrm{~mm}$ thick and $6 \mathrm{~mm}$ wide) were extracted by forging press cutting. These specimens were extracted along the rolling direction and used for determining the tensile properties of the specimens in different cycles.

The optical microstructures were observed using a JEOL JSM-6700F field emission scanning electron microscope (FESEM) with backscattered electron imaging (BEI).

\section{Result and Discussion}

3.1. Microstructure of $A l / M g$ Alloy. Figure 2 shows the microstructure of the perform sheet observed by optical microscope $(\mathrm{OM})$ for different $\mathrm{ARB}$ cycle process. Figures 2(a)-2(b) show the normal direction and the rolling direction, respectively. For the one cycle, the quantity of the strain was lower, and the shape of the $\mathrm{Mg}$ alloy showed longrange continuity. At this cycle, the deformation was mostly concentrated in the $\mathrm{Al}$ alloy. The deformation of $\mathrm{Mg}$ in the normal direction and rolling direction was different after one cycle of the ARB process. In the rolling direction, the elongation was much longer then the normal direction and resulted the $\mathrm{Mg}$ appeared split in the interface of $\mathrm{Mg} / \mathrm{Mg}$

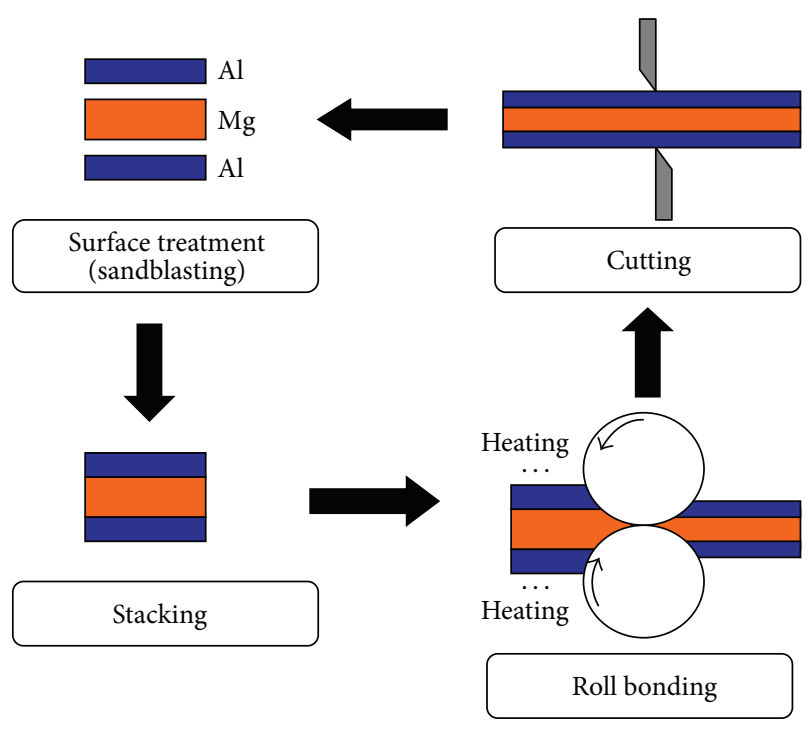

FIGURE 1: Schematic illustration of ARB process.

and had an irregular interface of $\mathrm{Mg} / \mathrm{Al}$. With increasing the strain for more cycles of ARB process, the $\mathrm{Mg}$ alloy gradually began to deform and separate obviously. The $\mathrm{Mg}$ alloy possessed critical strain and presented a long and flat shape distributed over a continuous $\mathrm{Al}$ alloy after four cycles of the ARB process.

3.2. Mechanical Properties and Fracture Behavior. The ultimate tensile strength $\left(\sigma_{\mathrm{UTS}}\right)$ and elongation curve of the firstcycle-fourth-cycle ARB specimens are shown in Figure 3. The third-cycle ARB specimen shows maximum $\sigma_{\mathrm{UTS}}, 117 \mathrm{MPa}$, and the first-cycle ARB specimen shows minimum $\sigma_{\mathrm{UTS}}$, $71 \mathrm{MPa}$. Elongations of the maximum and minimum values by approximately $0.75 \mathrm{~mm}$ and $0.53 \mathrm{~mm}$ occurred in the firstand fourth-cycle ARB specimens.

Figure 4 shows the fracture surface after the tensile test. The facture surfaces of the first- and second-cycle ARB specimens exhibit clear $\mathrm{Al} / \mathrm{Mg}$ interfaces that become blurred with an increase in the number of stacked layers after the third and fourth cycles of the ARB process. The cross section of the facture surface shows an irregular sawtooth shape. The formation of this shape is attributed to the alternate arrangement of $\mathrm{Al}$ and $\mathrm{Mg}$. The cleavage plane of $\mathrm{Mg}$ was shown in Figure 5(a) and makes an angle of approximately $45^{\circ}$ between the normal and the tensile directions in the first-cycle specimen. Hence, the Al layers support the overall stress of the first-cycle specimen during the tensile test. This causes the ultimate tensile strength to reduce greatly in firstcycle specimen. Only the Al layer undergoes deformation and elongation during the tensile test. Therefore, increasing the number of $\mathrm{ARB}$ cycles causes work hardening and reduction in the elongation of the Al layer. Increasing the number of layers by the ARB process will not only reduce the thickness of $\mathrm{Al}$ but will also decrease the deformation of the Al layer. Figure 6 shows the schematic diagram of the destruction and separation of $\mathrm{Al}$ and $\mathrm{Mg}$ during the tensile test. The interface 


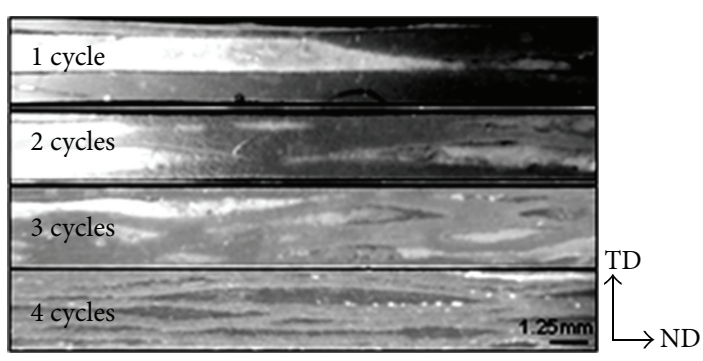

(a)

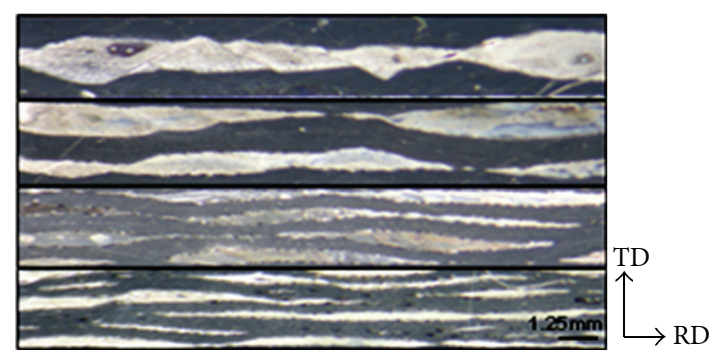

(b)

Figure 2: Cross-sectional OM microstructure of the $\mathrm{Al} / \mathrm{Mg}$ alloy with various cycles of $\mathrm{ARB}$ process: (a) normal direction, (b) rolling direction.

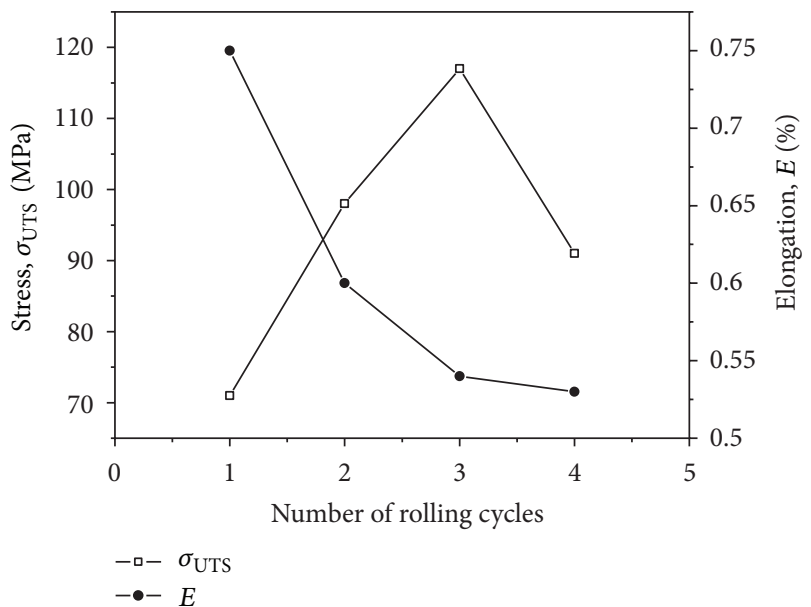

Figure 3: Variation of ultimate tensile strength and elongation of specimens in different cycles of ARB process.

of $\mathrm{Al}$ and $\mathrm{Mg}$ was broken with increasing stress, and this caused $\mathrm{Al}$ to extend and break.

In general, increase in tensile strength and grain refinement can be achieved by increasing the strain ratio after the rolling process. In this study, the ultimate tensile strength did not necessarily increase with increasing strain ratio of the $\mathrm{Al} / \mathrm{Mg}$ multilayer composite system. The results of the tensile test show that the ultimate tensile strength decreased greatly after the fourth cycle of the ARB process. It can be considered that the intermetallic compound improves the strength of the interface, but inner defects cause brittleness and fracture and reduce the tensile strength. Figure 7 shows an intermetallic layer with greater thickness and irregular cracks in the fourthcycle ARB specimen. The cracks propagate quickly because of the brittleness of the $\mathrm{Al}_{x} / \mathrm{Mg}_{y}$ intermetallic [22]. This behavior results in a reduction in the tensile strength. Figure 8 shows the initial crack in the intermetallic compound and the destruction of the compound after the tensile test. In Figure 9(a), the edge of the Al layer shows a rugged and rough surface, which was pulled away during the tensile test when the $\mathrm{Al} / \mathrm{Mg}$ interface was pulled apart. The fracture was induced by shear stress and the schematic diagram of $\mathrm{Al} / \mathrm{Mg}$ interface was pulled apart as shown in Figure 10. Figure 9(b) shows that the fragmentation of the intermetallic was distributed around the fracture face in the fourth cycle.

The image analysis result shows that the area ratio of $\mathrm{Al}$ and $\mathrm{Mg}$ between the first and fourth cycles was almost the same (Table 2). Therefore, the $\mathrm{Al}$ area can be considered as constant in all cycles. The angle $(\theta)$ is measured from the rolling direction to the interface between $\mathrm{Al}$ and $\mathrm{Mg}$ (as shown in Figure 11). Figure 12 shows the statistical bar chart, which displays the angle distribution. In the first-cycle $\mathrm{ARB}$ specimen, angles of most interfaces are between $25^{\circ}$ and $50^{\circ}$. After one more ARB process, the angles are between $0^{\circ}$ and $20^{\circ}$. After the third and fourth cycles, the angles are between $0^{\circ}$ and $5^{\circ}$ and $0^{\circ}$ and $10^{\circ}$, respectively. The variation of the interface angle could possibly lead to different stress conditions during the tensile test.

The stress acting on the interface could be divided into shear stress $(\tau)$ and normal stress $(B)$ (Figure 11). From the viewpoint of static stress equilibrium, we obtain

$$
\tau \cos \theta+B \sin \theta=\sigma .
$$

In the $\mathrm{Al} / \mathrm{Mg}$ composite, $\mathrm{Al}$ shows ductile fracture, but $\mathrm{Mg}$ is brittle. Hence, the total tensile stress must overcome at least the ultimate tensile strength of $\mathrm{Al}\left(\sigma_{\mathrm{UTS}, \mathrm{Al}}\right)$. Thus, the ultimate tensile strength of the ARB specimen can be written as follows:

$$
\begin{gathered}
\tau \cos \theta+B \sin \theta+\sigma_{\mathrm{UTS}, \mathrm{Al}}=\sigma_{\mathrm{UTS}, \mathrm{Total}}, \\
\tau \sin \theta=B \cos \theta
\end{gathered}
$$

Using (2) for the shear stress and normal stress, the following equation is obtained:

$$
\begin{gathered}
\tau\left(\frac{\cos ^{2} \theta+\sin \theta}{\cos \theta}\right)+\sigma_{\mathrm{UTS}, \mathrm{Al}}=\sigma_{\mathrm{UTS}, \text { Total }}, \\
B=\left(\sigma_{\mathrm{UTS}, \text { Total }}-\sigma_{\mathrm{UTS}, \mathrm{Al}}\right) \times\left(\frac{\sin \theta}{\cos ^{2} \theta+\sin \theta}\right),
\end{gathered}
$$

where $\sigma_{\text {UTS,Total }}$ could be obtained experimentally and $\sigma_{\text {UTS,Al }}$ was calculated by Hall-Petch equation [23]. The constants $\sigma_{0}=-23$ and $k=189$ were obtained by Ito et al. [24] in the case of grain size between 0.7 and $10 \mu \mathrm{m}$. The HallPetch equation is written as follows:

$$
\sigma_{\mathrm{UTS}, \mathrm{Al}}=-23+189\left(\frac{1}{d}\right)^{1 / 2} \text {. }
$$




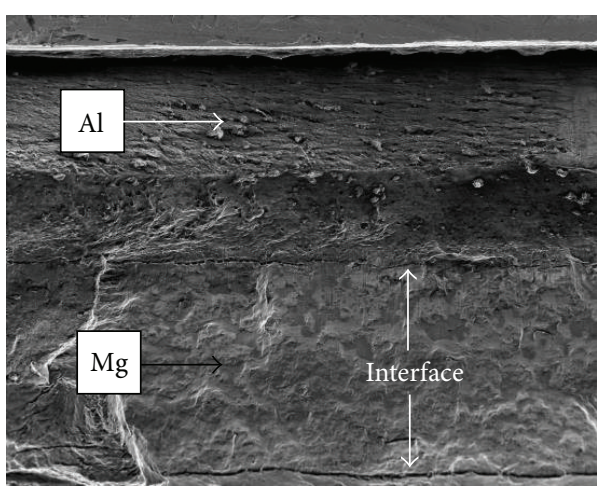

(a)

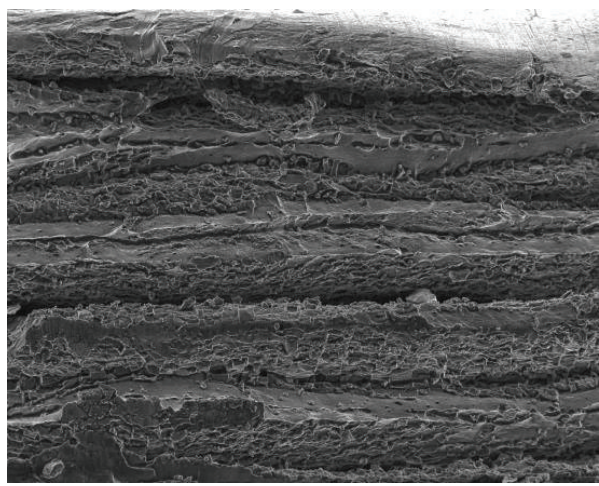

(c)

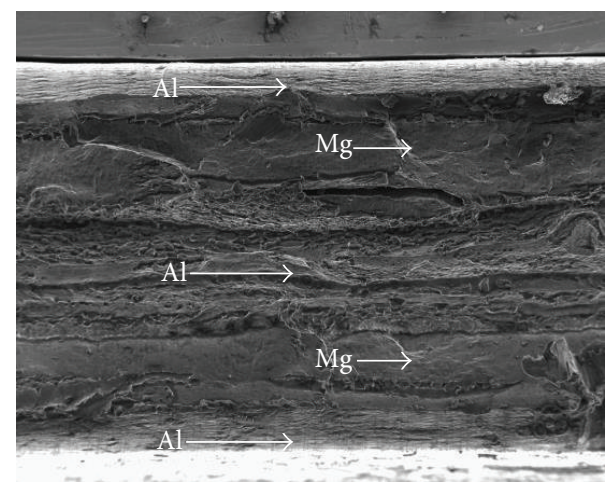

(b)

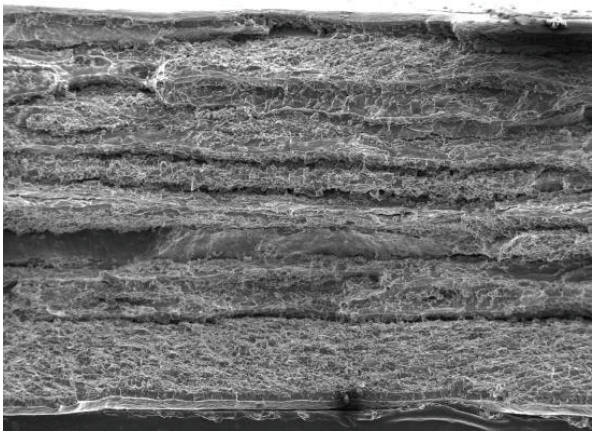

(d)

FIGURE 4: Fracture surface in different cycles of ARB process: (a) first cycle, (b) second cycle, (c) third cycle, and (d) fourth cycle.

The grain size $(d)$ of $\mathrm{Al}$ and calculated values of $\sigma_{\mathrm{UTS}, \mathrm{Al}}$ are listed in Table 1. The fourth-cycle and first-cycle specimens had the highest and lowest values of $\sigma_{\mathrm{UTS}, \mathrm{Al}}$, respectively. The cleavage goes deep into the Mg layer in the first-cycle ARB specimen (Figure 5(a)), and it reduces the tensile strength. Hence, the first-cycle ARB specimen values are unsuitable for being substituted into (3) to calculate the shear stress and normal stress. The fourth-cycle ARB specimen values are also unsuitable to be substituted into these equations, because of the thick intermetallic compound with numerous irregular defects. Therefore, the interface of shear stress and normal stress at different angles for the second- and third-cycle specimens was calculated and is shown in Figure 13. Because the third-cycle ARB specimen shows the highest ultimate tensile strength, the interface shear stress and normal stress of this specimen are higher than those for the second-cycle specimen. As the angle increases, the shear stress increases, but the normal stress decreases.

The Al/Mg interface angles decreased in the fourth-cycle ARB specimen, which resulted in high shear stress, and this specimen had greater intermetallic thickness and many irregular defects. If cracks are parallel to the shear stress, the cleavage in the intermetallic compound can be formed by the shear stress, and this leads to a decrease in the tensile strength.

Figure 14 shows the resultant stress $\left(\sigma_{\text {res }}\right)$ or critical fracture stress at different interface angles for the third- and
TABLE 1: Calculated values of $\sigma_{\mathrm{UTS}, \mathrm{Al}}$.

\begin{tabular}{lcccc}
\hline Cycle & 1 & 2 & 3 & 4 \\
\hline Grain size $(\mu \mathrm{m})$ & 1.077 & 1.002 & 0.927 & 0.926 \\
$\sigma_{\text {UTS,Al }}(\mathrm{MPa})$ & 162 & 166 & 181 & 182 \\
\hline
\end{tabular}

TABLE 2: Area ratio of $\mathrm{Al}$ and $\mathrm{Mg}$ in different cycles of $\mathrm{ARB}$ process.

\begin{tabular}{lcccc}
\hline Cycle & 1 & 2 & 3 & 4 \\
\hline Mg area (\%) & 30.5 & 36.1 & 33.7 & 29.7 \\
Al area (\%) & 69.5 & 63.9 & 66.3 & 70.3 \\
\hline
\end{tabular}

fourth-cycle ARB specimens. The resultant stress was derived from normal stress and shear stress. The maximum resultant stress of the second-cycle and third-cycle ARB specimens was found to be approximately $113 \mathrm{MPa}$ and $124 \mathrm{MPa}$, respectively, whereas the corresponding angle of the $\mathrm{Al} / \mathrm{Mg}$ interface was between $0^{\circ}$ and $5^{\circ}$. Further, the minimum resultant stress of the second-cycle and third-cycle ARB specimens was found to be approximately $93 \mathrm{MPa}$ and $103 \mathrm{MPa}$, respectively, whereas the corresponding angle of the $\mathrm{Al} / \mathrm{Mg}$ interface was between $30^{\circ}$ and $35^{\circ}$. The angle between $30^{\circ}$ and $35^{\circ}$ is the critical angle $\left(\theta_{\mathrm{CA}}\right)$. The resultant stress increased when the angle was lower or higher than the critical angle, and the interface was able to support more stress (critical fracture stress) during tensile tests. The interface could endure the smallest 


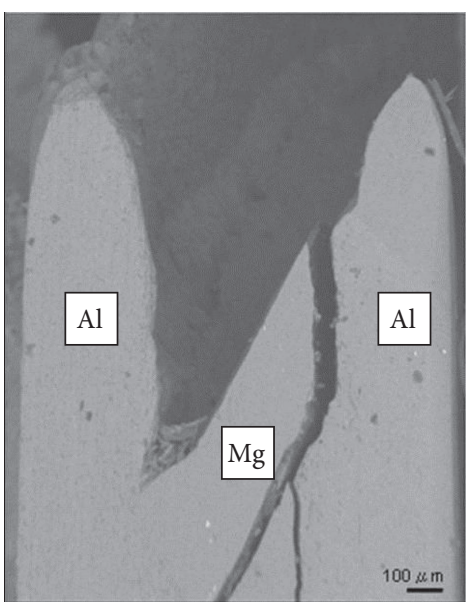

(a)

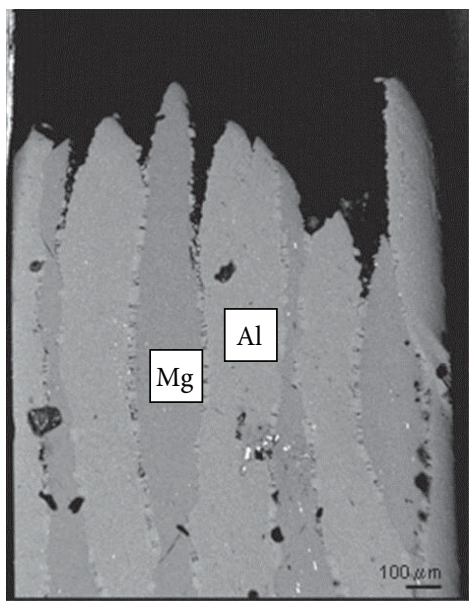

(c)

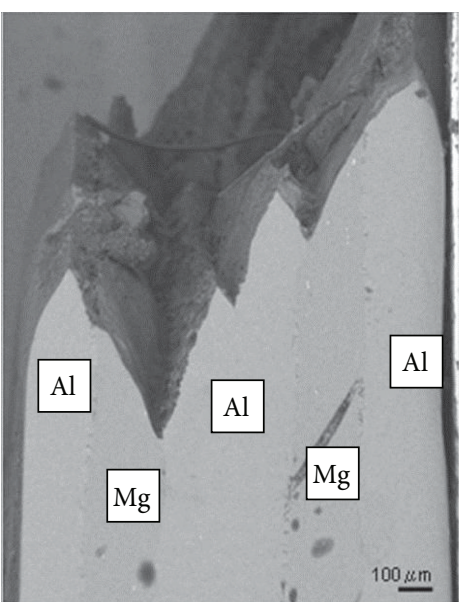

(b)

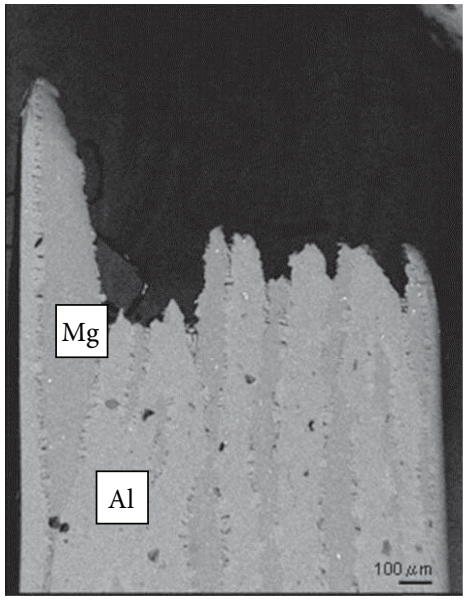

(d)

FIGURE 5: Cross section of fracture surface in different cycles of ARB process: (a) first cycle, (b) second cycle, (c) third cycle, and (d) fourth cycle.
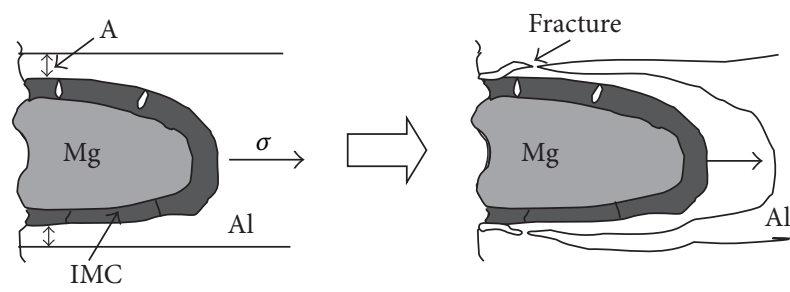

FIGURE 6: Schematic diagram of destruction and separation of $\mathrm{Al}$ and $\mathrm{Mg}$ during tensile test.

stress at the critical angle during tensile tests. In this study, the interface angle gradually increased at low angles and gradually decreased at high angles with an increase in the number of cycles of the ARB process. Most interface angles were below $35^{\circ}$ in the second and third cycles of the ARB process. In the third-cycle ARB specimen, approximately $44 \%$ of the interface angles were between $0^{\circ}$ and $5^{\circ}$. Therefore, the interface of the third-cycle ARB specimen can endure

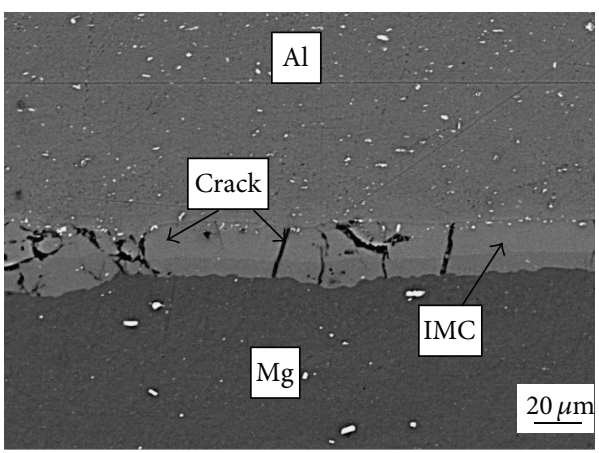

FIgURE 7: Cracks in intermetallic compound in fourth-cycle ARB specimen.

higher tensile stress than that of the second-cycle ARB specimen, and this results in an increase in the ultimate tensile strength. The ARB process not only varies the interface angle but also causes grain refinement to modify the tensile 


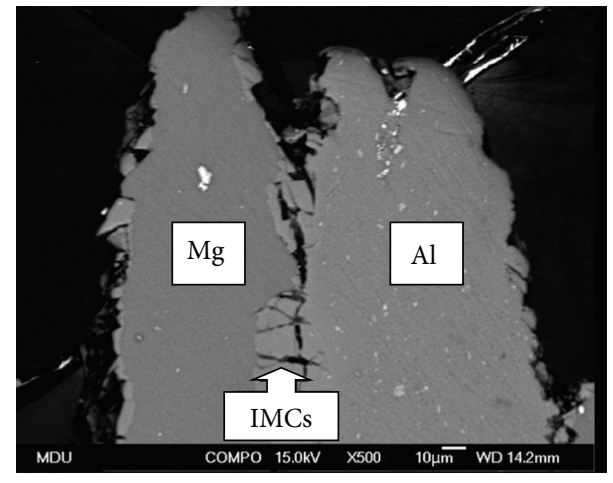

(a)

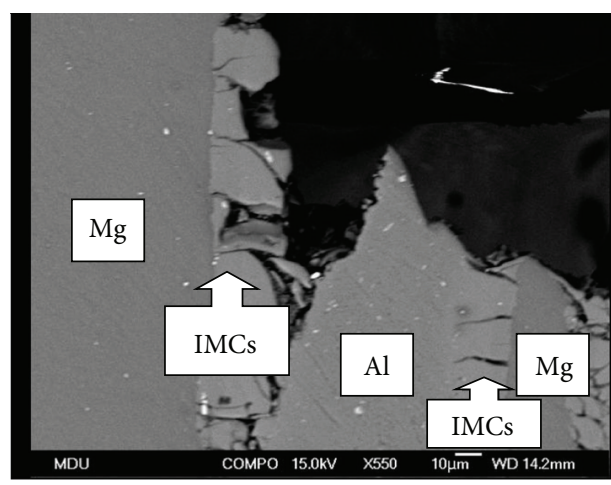

(b)

FIgURE 8: Cross section of fracture surface in fourth-cycle ARB specimen: destruction of intermetallic compound.

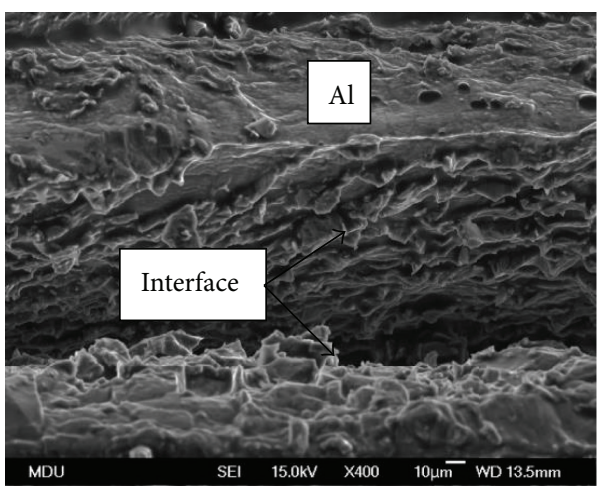

(a)

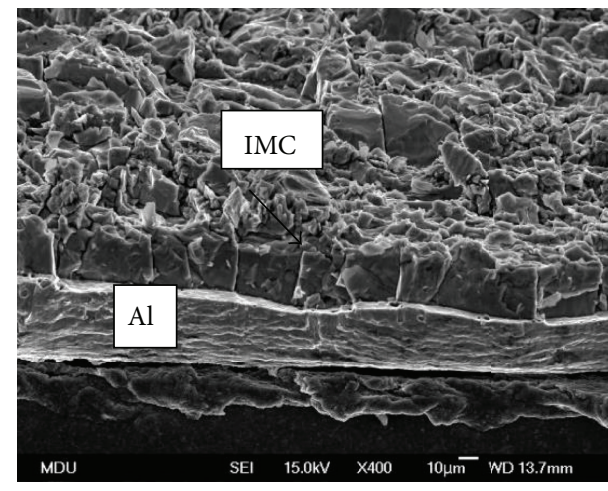

(b)

FIGURE 9: Structure of fracture surface in (a) third-cycle and (b) fourth-cycle ARB specimens.

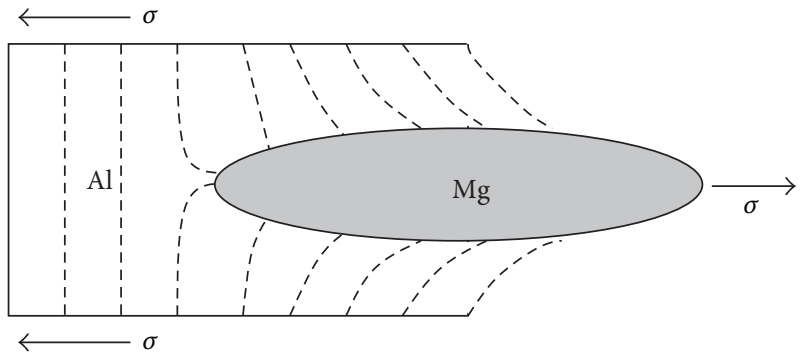

FIGURE 10: Schematic diagram of metal flow between interfaces of $\mathrm{Al}$ and $\mathrm{Mg}$.

properties. The ultimate tensile strength was improved by lower interface angles $\left(>30^{\circ}\right)$ after the ARB process. In the fourth cycle, if there were no defects in the intermetallic layer, the ultimate tensile strength would be higher than that in the other cycles. It could be considered that the other ARB specimens could use the same application of (3) and the result of stress condition would be similar to this study, if the ARB processes of specimens possessed the same composite matrix.

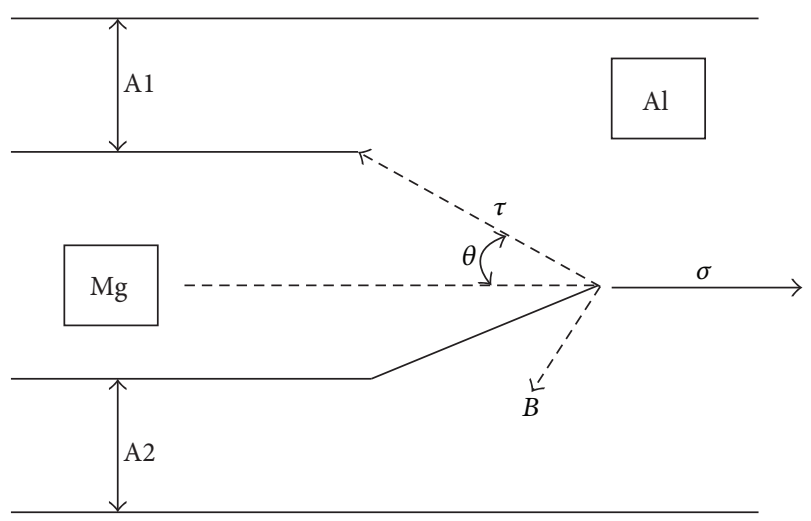

FIGURE 11: Schematic diagram of relation between interface angle and tensile stress direction.

\section{Conclusions}

Mechanical properties of specimens subjected to the first to fourth cycles of the ARB process were determined by tensile tests. The parameters of ultimate tensile strength, elongation, resultant stress, and critical interface angle were calculated 


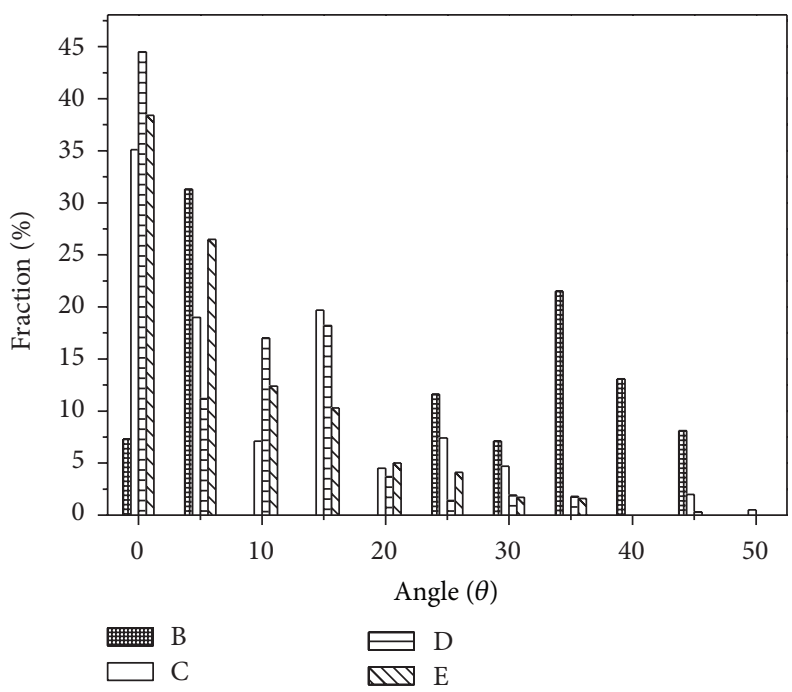

Figure 12: Angles in different cycles of ARB process: (a) first cycle, (b) second cycle, (c) third cycle, and (d) fourth cycle.

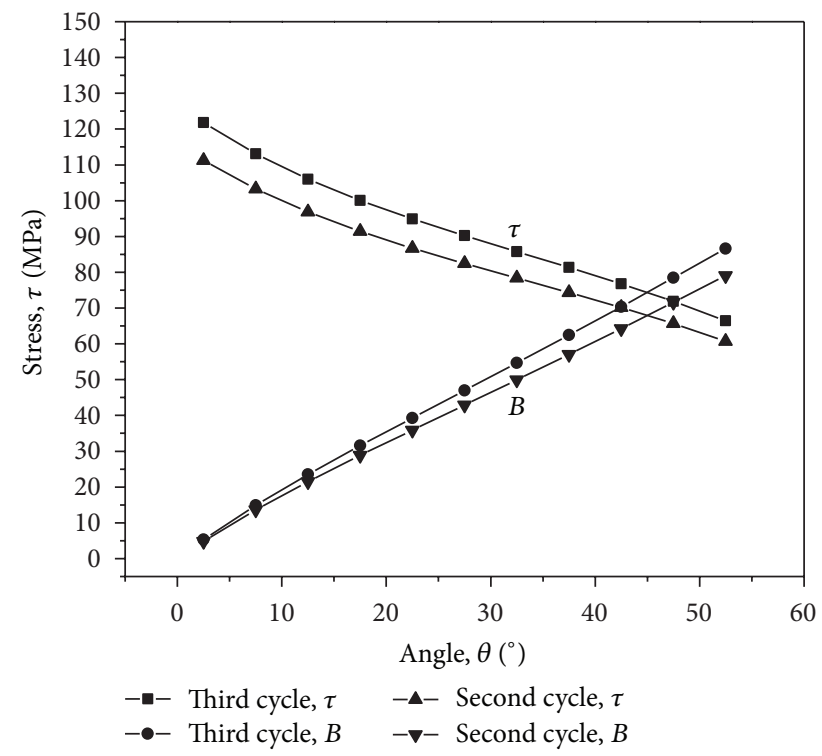

FIGURE 13: Shear stress and normal stress at the different angles in second- and third-cycle ARB specimens.

experimentally. The results of the study are summarized as follows.

(1) The third-cycle ARB specimen had the highest tensile strength, due to its low $\mathrm{Al} / \mathrm{Mg}$ interface angle, which enhances the ability of the interface bonding to resist the shear stress. The tensile strength of the firstcycle ARB specimen was reduced by the cleavage and propagation of the crack deep into the Mg layer. In the fourth-cycle ARB specimen, defects induced a crack in the intermetallic layer, which led to a decrease in tensile strength.

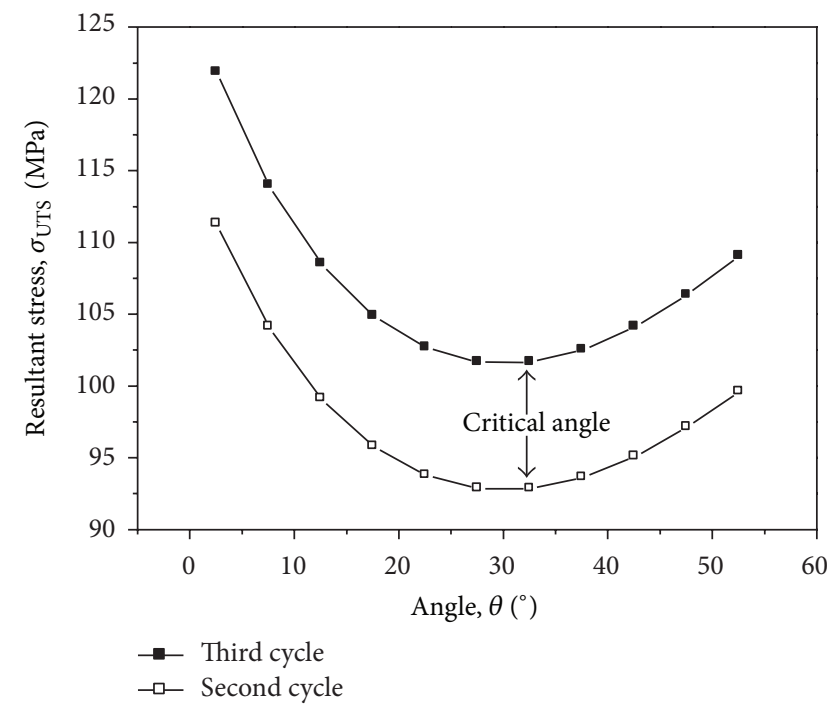

FIgURE 14: Distribution of resultant stress for different angles in second- and third-cycle specimens.

(2) The maximum resultant stress of the second- and third-cycle ARB specimens was found to be approximately $113 \mathrm{MPa}$ and $124 \mathrm{MPa}$, respectively, whereas the corresponding angle of the $\mathrm{Al} / \mathrm{Mg}$ interface was between $0^{\circ}$ and $5^{\circ}$. The minimum resultant stress of the second- and third-cycle ARB specimens was found to be approximately $93 \mathrm{MPa}$ and $103 \mathrm{MPa}$, respectively, and the corresponding interface angle was between $30^{\circ}$ and $35^{\circ}$.

(3) The $\mathrm{Al} / \mathrm{Mg}$ interface angle between $30^{\circ}$ and $35^{\circ}$ is the critical angle. A higher or lower interface angle improves the tensile strength.

(4) The ultimate tensile strength was improved by a low angle of interface bonding after the ARB process. 


\section{Acknowledgment}

The authors are obligated to thank the National Science Council of the Taiwan for the financial support under Projects nos. NSC 100-ET-E-005-001-ET, 100-EC-17-A-08-S1-117, NSC 101-2811-E-005-001, and NSC 101-2623-E-005-002-ET.

\section{References}

[1] R. G. Hoagland, T. E. Mitchell, J. P. Hirth, and H. Kung, "On the strengthening effects of interfaces in multilayer fcc metallic composites," Philosophical Magazine A, vol. 82, no. 4, pp. 643664, 2002.

[2] S. I. Rao and P. M. Hazzledine, "Atomistic simulations of dislocation-interface interactions in the $\mathrm{Cu}-\mathrm{Ni}$ multilayer system," Philosophical Magazine A, vol. 80, no. 9, pp. 2011-2040, 2000.

[3] Y. Saito, N. Tsuji, H. Utsunomiya, T. Sakai, and R. G. Hong, "Ultra-fine grained bulk aluminum produced by accumulative roll-bonding (ARB) process," Scripta Materialia, vol. 39, no. 9, pp. 1221-1227, 1998.

[4] Y. Saito, H. Utsunomiya, N. Tsuji, and T. Sakai, "Novel ultrahigh straining process for bulk materials development of the accumulative roll-bonding (ARB) process," Acta Materialia, vol. 47, no. 2, pp. 579-583, 1999.

[5] N. Tsuji, Y. Saito, H. Utsunomiya, and S. Tanigawa, "Ultrafine grained bulk steel produced by accumulative roll-bonding (ARB) process," Scripta Materialia, vol. 40, no. 7, pp. 795-800, 1999.

[6] P. J. Hsieh, Y. C. Lo, J. C. Huang, and S. P. Ju, “On the latest stage of transformation from nanocrystalline to amorphous phases during ARB: simulation and experiment," Intermetallics, vol. 14, no. 8-9, pp. 924-930, 2006.

[7] S. H. Lee, Y. Saito, N. Tsuji, H. Utsunomiya, and T. Sakai, "Role of shear strain in ultragrain refinement by accumulative rollbonding (ARB) process," Scripta Materialia, vol. 46, no. 4, pp. 281-285, 2002.

[8] Z. P. Xing, S. B. Kang, and H. W. Kim, "Softening behavior of 8011 alloy produced by accumulative roll bonding process," Scripta Materialia, vol. 45, no. 5, pp. 597-604, 2001.

[9] H. W. Kim, S. B. Kang, N. Tsuji, and Y. Minamino, "Elongation increase in ultra-fine grained Al-Fe-Si alloy sheets," Acta Materialia, vol. 53, no. 6, pp. 1737-1749, 2005.

[10] N. Kamikawa, N. Tsuji, X. Huang, and N. Hansen, "Quantification of annealed microstructures in ARB processed aluminum," Acta Materialia, vol. 54, no. 11, pp. 3055-3066, 2006.

[11] N. Kamikawa, T. Sakai, and N. Tsuji, "Effect of redundant shear strain on microstructure and texture evolution during accumulative roll-bonding in ultralow carbon IF steel," Acta Materialia, vol. 55, no. 17, pp. 5873-5888, 2007.

[12] N. Kamikawa, N. Tsuji, and Y. Minamino, "Microstructure and texture through thickness of ultralow carbon IF steel sheet severely deformed by accumulative roll-bonding," Science and Technology of Advanced Materials, vol. 5, no. 1-2, pp. 163-172, 2004.

[13] S. H. Lee, C. H. Lee, S. Z. Han, and C. Y. Lim, "Annealing characteristics of nano-grained oxygen free copper processed by accumulative roll-bonding process," Journal of Nanoscience and Nanotechnology, vol. 6, no. 11, pp. 3661-3664, 2006.
[14] M. C. Chen, H. C. Hsieh, and W. Wu, "The evolution of microstructures and mechanical properties during accumulative roll bonding of $\mathrm{Al} / \mathrm{Mg}$ composite," Journal of Alloys and Compounds, vol. 416, no. 1-2, pp. 169-172, 2006.

[15] G. Min, J. M. Lee, S. B. Kang, and H. W. Kim, "Evolution of microstructure for multilayered $\mathrm{Al} / \mathrm{Ni}$ composites by accumulative roll bonding process," Materials Letters, vol. 60, no. 27, pp. 3255-3259, 2006.

[16] R. Zhang and V. L. Acoff, "Processing sheet materials by accumulative roll bonding and reaction annealing from $\mathrm{Ti} / \mathrm{Al} / \mathrm{Nb}$ elemental foils," Materials Science and Engineering A, vol. 463, no. 1-2, pp. 67-73, 2007.

[17] E. M. Tanguep Njiokep, M. Salamon, and H. Mehrer, "Growth of intermetallic phases in the Al-Mg system," Defect and Diffusion Forum, no. 194-199, pp. 1581-1586, 2001.

[18] H. Y. Kim, D. S. Chung, and S. H. Hong, "Reaction synthesis and microstructures of $\mathrm{NiAl} / \mathrm{Ni}$ micro-laminated composites," Materials Science and Engineering A, vol. 396, no. 1-2, pp. 376384, 2005.

[19] M. Mita, M. Kajihara, N. Kurokawa, and K. Sakamoto, "Growth behavior of Ni3Sn4 layer during reactive diffusion between $\mathrm{Ni}$ and $\mathrm{Sn}$ at solid-state temperatures," Materials Science and Engineering A, vol. 403, no. 1-2, pp. 269-275, 2005.

[20] M. C. Chen, C. C. Hsieh, and W. Wu, "Microstructural characterization of $\mathrm{Al} / \mathrm{Mg}$ alloy interdiffusion mechanism during accumulative roll bonding," Metals and Materials International, vol. 13, no. 3, pp. 201-205, 2007.

[21] M. C. Chen, C. W. Kuo, C. M. Chang, C. C. Hsieh, Y. Y. Chang, and $\mathrm{W}$. Wu, "Diffusion and formation of intermetallic compounds during accumulative roll-bonding of $\mathrm{Al} / \mathrm{Mg}$ alloys," Materials Transactions, vol. 48, no. 10, pp. 2595-2598, 2007.

[22] N. Tsuji, T. Iwata, M. Sato, S. Fujimoto, and Y. Minamino, "Aging behavior of ultrafine grained $\mathrm{Al}-2 \mathrm{wt} \% \mathrm{Cu}$ alloy severely deformed by accumulative roll bonding," Science and Technology of Advanced Materials, vol. 5, no. 1-2, pp. 173-180, 2004.

[23] M. Zhao, J. C. Li, and Q. Jiang, "Hall-Petch relationship in nanometer size range," Journal of Alloys and Compounds, vol. 361, no. 1-2, pp. 160-164, 2003.

[24] Y. Ito, N. Tsuji, Y. Saito, H. Utsunomiya, and T. Sakai, "Change in microstructure and mechanical properties of ultrafine grained aluminum during annealing," Nippon Kinzoku Gakkaishi/Journal of the Japan Institute of Metals, vol. 64, no. 6, pp. 429-437, 2000. 

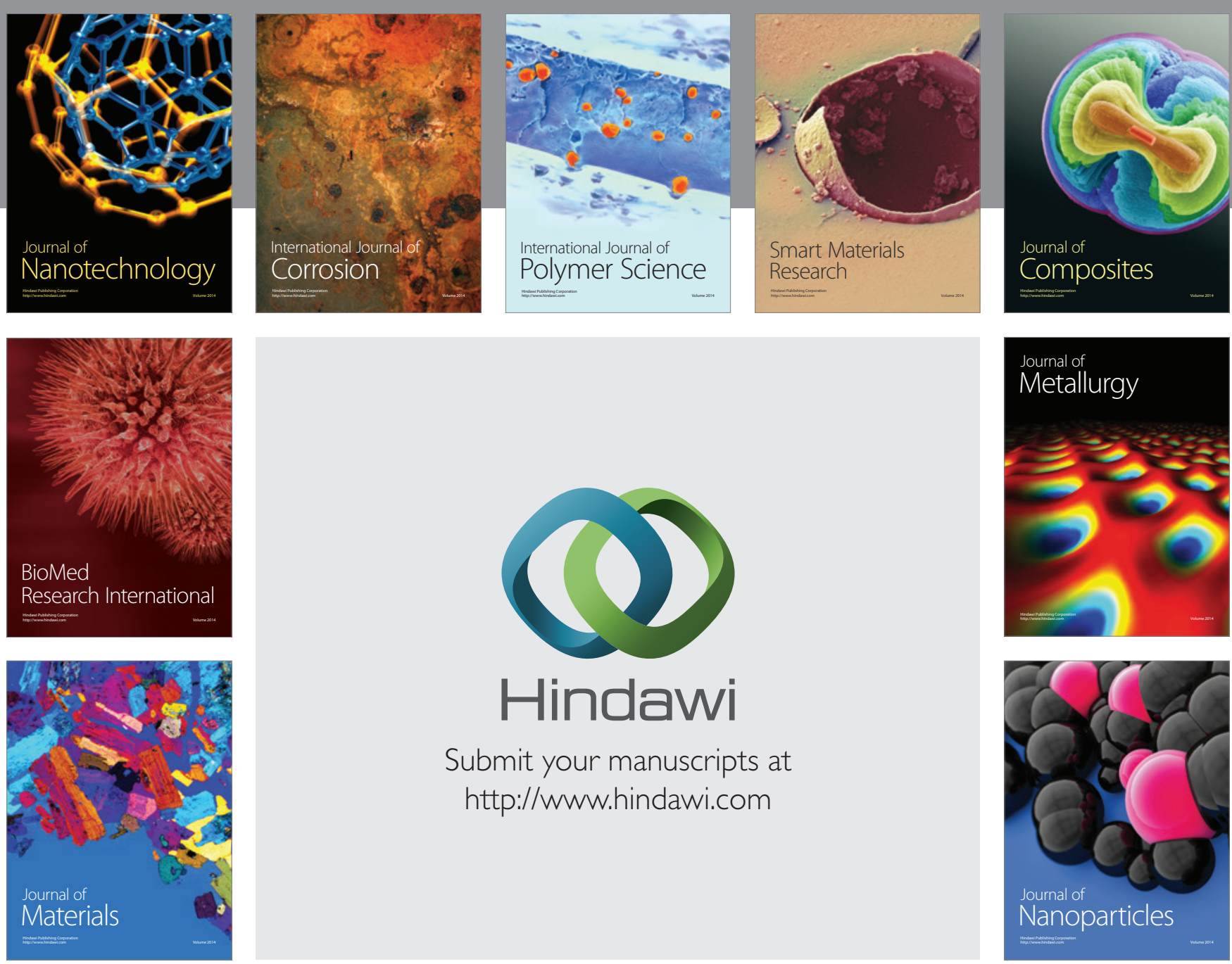

Submit your manuscripts at http://www.hindawi.com
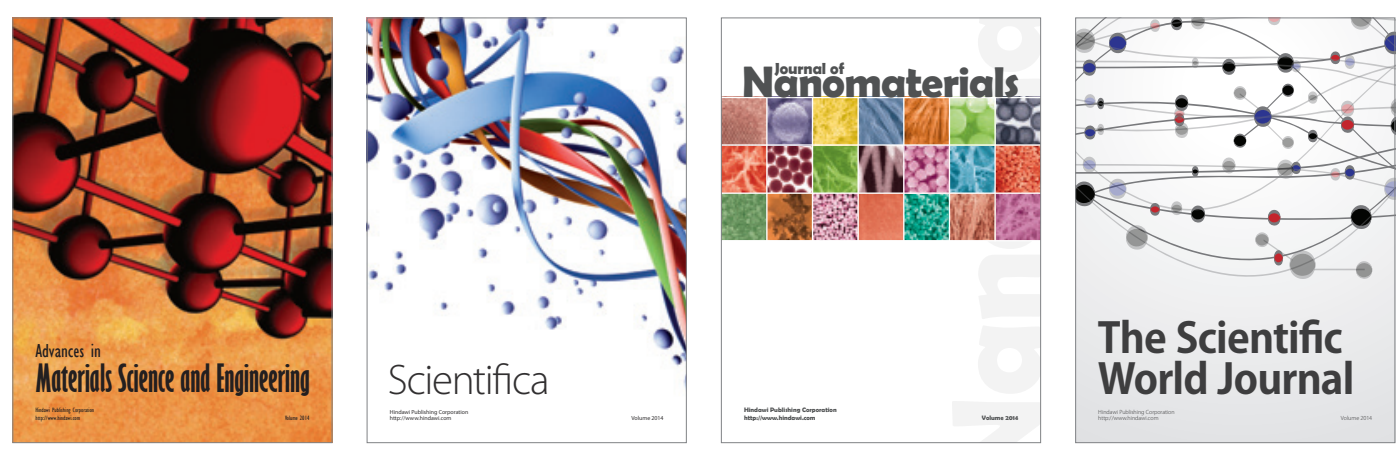

\section{The Scientific World Journal}
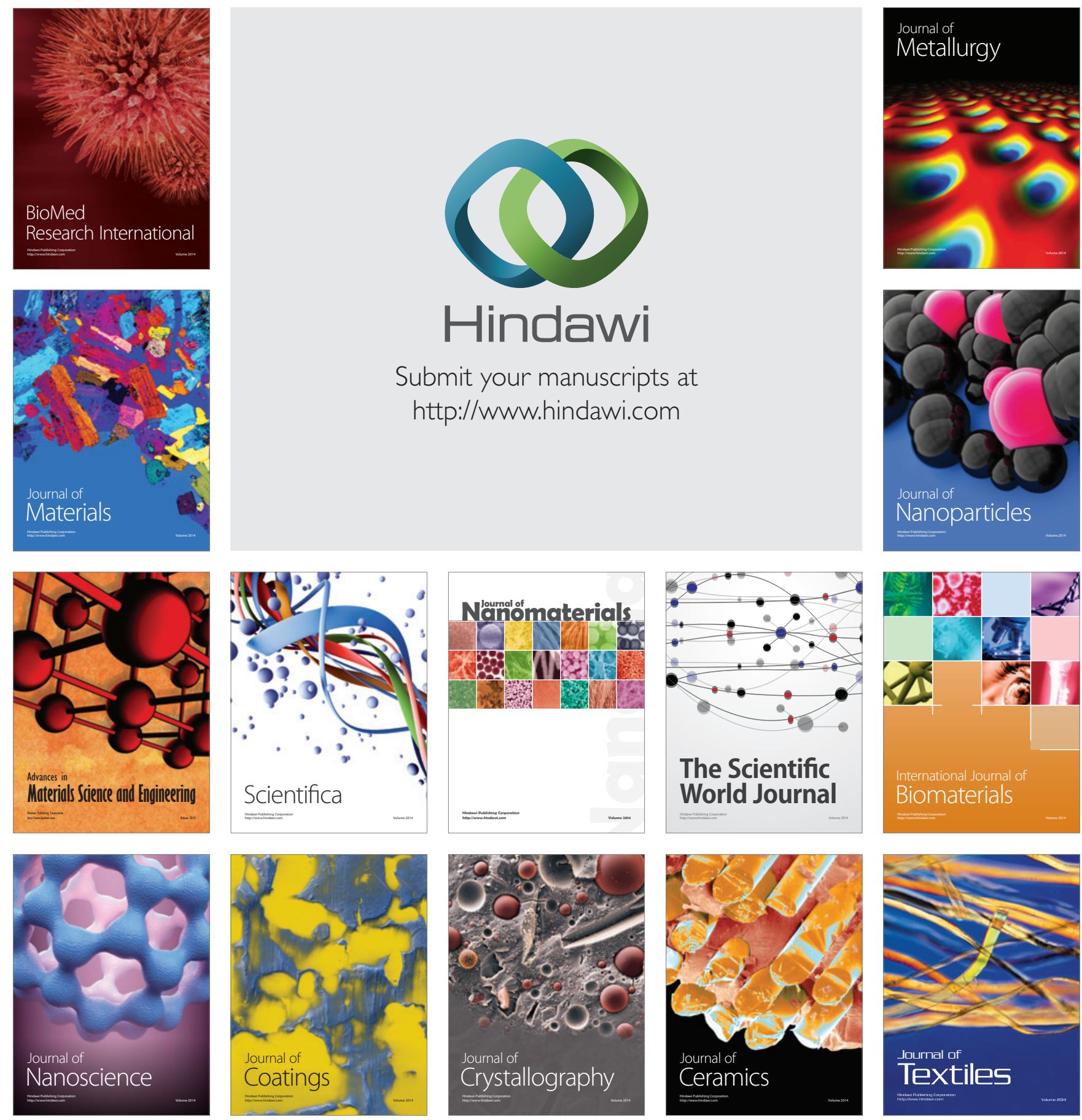